M.I. Savchuk ${ }^{\text {a }}$, E. S. Starnovskaya ${ }^{\text {ab }}$, Y. K. Shtaitz ${ }^{\text {, }}$, A.P. Krinochkin ${ }^{\text {ab }}$, D. S. Kopchuk ${ }^{\text {ab }}$, S. Santra ${ }^{a}$, M. Rahman ${ }^{\text {a }}$, G. V. Zyryanov ${ }^{\text {ab }}$, V.L. Rusinov ${ }^{\text {ab }}$, O.N. Chupakhin ${ }^{\text {ab }}$

${ }^{a}$ Ural Federal University named after the first President of Russia B. N. Yeltsin, 620002, 19 Mira St., Ekaterinburg, Russia

${ }^{b}$ I. Ya. Postovsky Institute of Organic Synthesis of RAS (Ural Branch), 620990, 22/20 S. Kovalevskoy/Akademicheskaya St., Ekaterinburg, Russia *email: g.v.zyrianov@urfu.ru

\title{
Direct synthesis of 5-arylethynyl-1,2,4-triazines via direct $\mathrm{CH}-$ functionalization
}

An efficient synthetic approach towards 5-arylethynyl-1,2,4-triazines via direct $\mathrm{C}-\mathrm{H}$-functionalization of $5-\mathrm{H}-1,2,4$-triazines in reaction with lithium acetylenes is reported.

Keywords: C-H-Functionalization, 1,2,4-triazines; acetylenes lithium salts; 5-arylethynyl1,2,4-triazines

Received: 05.08.2020. Accepted: 01.09.2020. Published: 07.10.2020.

(c) M. I. Savchuk, E. S. Starnovskaya, Y. K. Shtaitz, A. P. Krinochkin, D. S. Kopchuk, S. Santra, M. Rahman, G. V. Zyryanov, V. L. Rusinov, O. N. Chupakhin, 2020

\section{Introduction}

Heterocyclic acetylenes are widely used in various heterocyclization reactions [1], especially via click reactions [2]. Acetylene spacers are presented in a number of conjugated heterocyclic chromophores [3]. Additionally, some heterocyclic acetylenes are known posses with biological activities, for instance as antihypertensive agents [4].

The object of study of this work - 5-arylethynyl-1,2,4-triazines - are promising substrates for the preparation of various classes of compounds with unique applied properties. For example, by the transformation of the 1,2,4-triazine ring into the pyridine one via the aza-Diels-Alder reaction with vatious dienophiles, the corresponding pyridines can be obtained, including 2,2' - bipyridine ligands [4]. In addition, arylethynyl substituted 1,2,3-triazoles were obtained in the reaction of the corresponding 3- (2-pyridyl) - 1,2,4-triazines with aryne intermediates [5-6]. Also, by the chemical transformation of 5-arylethynyl the corresponding 5-phenacyl1,2,4-triazines could be obtained [7-8], which in turn can be transformed into 5-methyl-1,2,4-triazines [9].

Among the reported methods for the synthesis of 5-arylethynyl-1,2,4-triazines, the use of the Sonogashira cross-coupling can be highlighted [10], and in this case 5-iodine or 5-chloro-1,2,4-triazines were used as reactants In addition, the direct introduction of an arylethynyl moiety via the $\mathrm{C}$ - $\mathrm{H}$ functionalization of 1,2,4-triazine-4-oxides in the reaction with the lithium salt of acetylene are described by using 
deoxygenative aromatization pathway, and the benzoyl chloride was used as an acylating agent $[5,11]$. The interaction of non-activated 1,2,4-triazines with the lithium salt of arylacetylene is also described, however, the corresponding 5-styryl-1,2,4-triazines were the main reaction products [12-13]. In this aspect, it should be noted the greater availability of 1,2,4-triazines compare to 1,2,4-triazine-4-oxides; and the preparation of ethynyl derivatives starting from 1,2,4-triazines looks more attractive.

In this article, we wish to report an efficient synthesis of 5-arylethynyl-1,2,4-triazines 1 via direct $\mathrm{C}$ - $\mathrm{H}$-functionalization of 5- $H$-1,2,4-triazines 2 with lithium arylacetylenes.

\section{Experimental part}

${ }^{1} \mathrm{H}$ NMR spectra were recorded on a Bruker Avance-400 spectrometer (400 MHz), the internal standard was $\mathrm{SiMe}_{4}$. Mass spectra (ionization type - electrospray) were recorded on a MicrOTOF-Q II instrument from Bruker Daltonics (Bremen, Germany). Elemental analysis was performed on a Perkin Elmer PE 2400 II CHN analyzer. The starting 1,2,4-triazine 2 was obtained according to the described method [14].

A general procedure for the synthesis of of arylethynyl-1,2,4-triazines 1:

A solution of $\mathrm{n}$-BuLi in hexane $(2.5 \mathrm{M}$, $0.8 \mathrm{ml}$ ) was added to a solution of the corresponding arylacetylene $(2 \mathrm{mmol})$ in dry THF (4 ml) in a Schlenk flask at a temperature of $-78^{\circ} \mathrm{C}$ in an argon atmosphere, and the resulting mixture was stirred for $5 \mathrm{~min}$. Then the solution of the corresponding 1,2,4-triazine $\mathbf{1}(1.6 \mathrm{mmol})$ in dry toluene $(35 \mathrm{ml})$ was added, and a minute later a solution of DDQ (305 mg, $1.34 \mathrm{mmol}$ ) in dry toluene $(10 \mathrm{ml})$ was added. The resulting mixture was stirred for $3 \mathrm{~h}$ at $78^{\circ} \mathrm{C}$ to room temperature. After that methanol $(10 \mathrm{ml})$ was added, and the reaction mixture stirred for $5 \mathrm{~min}$ and the solvents were removed under reduced pressure. The resulting oily residue was purified by column chromatography (neutral alumina, eluent: dichloromethane) to afford the desired products.
3- (2-Pyridyl) - 6-phenyl-5-phenylethynyl-1,2,4-triazine (1a). Yield $565 \mathrm{mg}$ (1.7 mmol, 85\%). Rf 0.6. M.p. $142-144^{\circ} \mathrm{C}$. $\mathrm{NMR}{ }^{1} \mathrm{H}\left(\mathrm{CDCl}^{3}, \delta, \mathrm{ppm}\right): 7.37-7.41(\mathrm{~m}$, $2 \mathrm{H}, \mathrm{PhC} \equiv \mathrm{C}), 7.43-7.55(\mathrm{~m}, 4 \mathrm{H}, \mathrm{PhC} \equiv \mathrm{C}$, $\mathrm{H}-5$ (py)), 7.59-7.63 ( $\mathrm{m}, 3 \mathrm{H}, \mathrm{Ph}), 7.94-$ 7.99 (ddd, $1 \mathrm{H},{ }^{3} \mathrm{~J} 8.0,8.0 \mathrm{~Hz},{ }^{4} \mathrm{~J} 2.0 \mathrm{~Hz}, \mathrm{H}-4$ (py)), 8.19-8.22 (m, 2H, Ph), 8.75 (dd, $1 \mathrm{H},{ }^{3} \mathrm{~J} 8.0 \mathrm{~Hz},{ }^{4} \mathrm{~J} 1.0 \mathrm{~Hz}, \mathrm{H}-3$ (py)), 8.96 (dd, $1 \mathrm{H},{ }^{3} J 4.8 \mathrm{~Hz},{ }^{4} J 2.0 \mathrm{~Hz}, \mathrm{H}-6$ (py)). ${ }^{13} \mathrm{C}$ NMR $\left(\mathrm{CDCl}_{3}, \delta, \mathrm{ppm}\right): 86.5$ (C-sp), 100.8 (C-sp), 120.8, 124.2, 125.7, 128.5, $128.7,129.5,130.7,132.6,133.9,137.2$, 142.6, 150.6, 152.4, 157.7, 160.7. ESI-MS, $\mathrm{m} / \mathrm{z}: 335.13(\mathrm{M}+\mathrm{H})^{+}$. Found, \%: C 78.82, $\mathrm{H}$ 4.01, N 16.55. $\mathrm{C}_{22} \mathrm{H}_{14} \mathrm{~N}_{4}$. Calculated, \%: C 79.02, H 4.22, N 16.76.

5 - ((4-Methoxyphenyl) ethynyl) 3- (pyridin-2-yl) - 6-phenyl-1,2,4-triazine (1b). Yield $515 \mathrm{mg}(1.41 \mathrm{mmol}, 88 \%)$. $\mathrm{NMR}{ }^{1} \mathrm{H}\left(\mathrm{CDCl}_{3}, \delta, \mathrm{ppm}\right): 3.85(\mathrm{~m}, 3 \mathrm{H}$, $\left.\mathrm{OCH}_{3}\right), 6.89\left(\mathrm{~m}, 2 \mathrm{H}, \mathrm{C}_{6} \mathrm{H}_{4}\right), 7.45-7.54(\mathrm{~m}$, $3 \mathrm{H}, \mathrm{C}_{6} \mathrm{H}_{4}, \mathrm{H}-5$ (py)), 7.55-7.64 (m, 3H, $\mathrm{Ph}$ ), 7.95 (ddd, $1 \mathrm{H},{ }^{3} J 7.6 \mathrm{~Hz}, 7.6 \mathrm{~Hz},{ }^{4} J 1.6$ $\mathrm{Hz}, \mathrm{H}-4$ (py)), 8.17-8.23 (m, 2H, Ph), 8.74 (d, $1 \mathrm{H},{ }^{3} J 8.0 \mathrm{~Hz}, \mathrm{H}-3$ (py)), 8.94 (d, $1 \mathrm{H}$, ${ }^{3} J 4.8 \mathrm{~Hz}, \mathrm{H}-6$ (py)). ESI-MS, m/z: 365.14 $(\mathrm{M}+\mathrm{H})^{+}$. Found, \%: C 75.70, H 4.30, $\mathrm{N}$ 15.25. $\mathrm{C}_{23} \mathrm{H}_{16} \mathrm{~N}_{4} \mathrm{O}$. Calculated,\%: C 75.81, $\mathrm{H} 4.43, \mathrm{~N} 15.37$. 


\section{Results and discussion}

The previously proposed mechanism [14] for the reaction of 1,2,4-triazines and lithium-acetylenes is presented on the scheme 1.

According to the mechanism, at the first stage, the corresponding $\sigma^{\mathrm{H}}$-adduct A is formed, which further undergoes a 1,2-hydride shift affording the formation of the corresponding styryl substituent. And the treatment of the reaction mixture with methanol at the final stage leads to the products 3 . Obviously, to block the pathway A for the reaction, the $\sigma \mathrm{H}$-adduct $\mathrm{A}$ need to be treated with and oxidant to form 5-ethynyl-1,2,4-triazine 1, which no longer turn into 5-styryl derivative 3 Indeed, it was found that the addition of an oxidizing agent, such as 2,3-dichloro-5,6-dicyanobenzoquinone (DDQ), 10 minutes after the initiation of the reaction between 1,2,4-triazine and the arylacetylene lithium salt allowed us to obtain the corresponding 5-phenylethynyl- 1,2,4-triazines 1 in up to $88 \%$ yields (way B), and they were isolated using column chromatography.

The structure of products $\mathbf{1}$ was confirmed based on the data of NMR ${ }^{1} \mathrm{H},{ }^{13} \mathrm{C}$ spectroscopy, mass spectrometry, and elemental analysis. Thus, in the ${ }^{13} \mathrm{C}$ NMR spectra, the signals of $s p$-hybrid carbon atoms in the range of $86.5-100.8 \mathrm{ppm}$ can be observed. The spectral data of compound 1a correspond to those previously published during its synthesis by an alternative method [5].

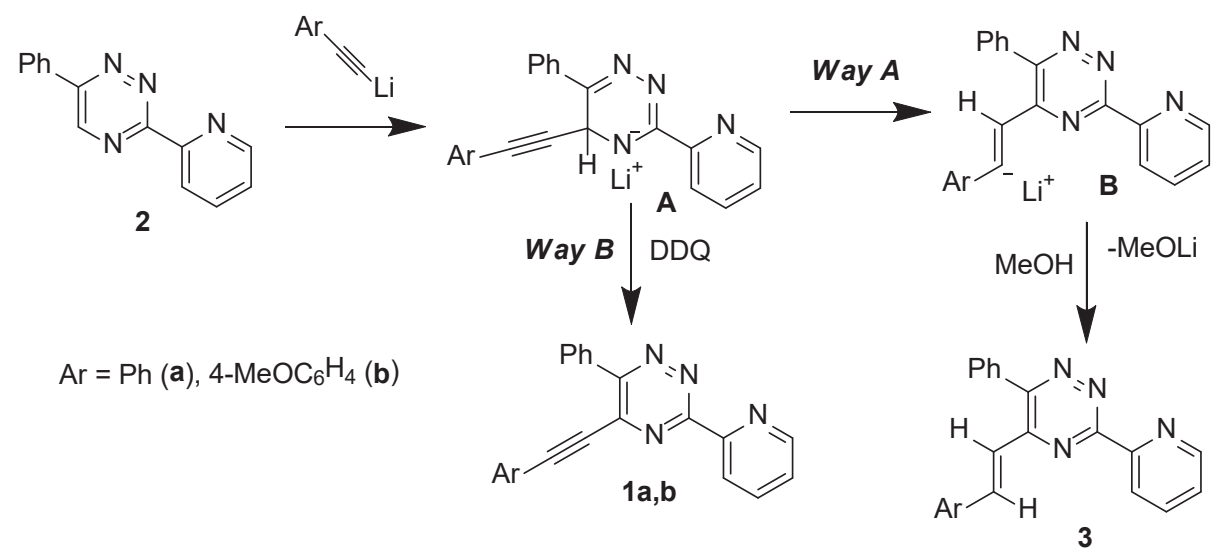

Scheme 1. Mechanism of reaction of 5-H-1,2,4-triazines 2 with lithium-acetylenes

\section{Conclusions}

An efficient synthetic approach towards 5-arylethynyl-1,2,4-triazines via direct C$\mathrm{H}$-functionalization of 5-H-1,2,4-triazines in reaction with lithium-acetylenes was re- ported. This method could serve as a possible $P d$-free alternative to the Sonogashira cross-coupling.

\section{Acknowledgements}

This work was supported by the Russian Science Foundation (Grant \# 20-13-00142) and Grants Council of the President of the Russian Federation (no. NSh-2700.2020.3). 


\section{References}

1. a) Heravi MM, Sadjadi S. Recent advances in the application of the Sonogashira method in the synthesis of heterocyclic compounds. Tetrahedron. 2009;65:77617775. DOI: 10.1016/j.tet.2009.06.028 ; b) Verma AK, Jha RR, Chaudhary R, Tiwari RK, Reddy KSK, Danodia A. Copper-catalyzed tandem synthesis of indolo-, pyrrolo[2,1-a]isoquinolines, naphthyridines and bisindolo/pyrrolo[2,1-a]isoquinolines via hydroamination of ortho-haloarylalkynes followed by C-2 arylation. J Org Chem. 2012;77:8191-8205.

DOI: $10.1021 /$ jo301572p

2. a) Pasini $D$. The Click Reaction as an Efficient Tool for the Construction of Macrocyclic Structures. Molecules. 2013;18:9512-9530. DOI: 10.3390/molecules18089512 ; b) Hiroki H, Ogata K, Fukuzawa S-I. 2-Ethynylpyridine-promoted rapid copper(i) chloride catalyzed azide - alkyne cycloaddition reaction in water. Synlett. 2013;24:843-846. DOI: 10.1055/s-0032-1318488 ; c) Kovács S, Zih-Peréni K, Révész Á, Novák Z. Copper on iron: catalyst and scavenger for azide - alkyne cycloaddition. Synthesis. 2012;44:3722-3730.

DOI: $10.1055 / \mathrm{s}-0032-1317697$

3. a) Benniston AC, Harriman A, Lawrie DJ, Mayeux A, Rafferty K, Russell OD. A general purpose reporter for cations: absorption, fluorescence and electrochemical sensing of zinc(ii). Dalton Trans. 2003;4762-4769. DOI: 10.1039/B313413J ; b) Joshi HS, Jamshidi R, Tor Y. Conjugated 1,10-Phenanthrolines as Tunable Fluorophores. Angew Chem Int Ed. 1999;38:2722-2725.

DOI: 10.1002/(SICI)1521-3773(19990917)38:18<2721::AID-ANIE2721>3.0.CO;2-5

4. John R. Carson, inventor; McNeilab, Inc., assignee. Heteroaromatic acetylenes useful as anthypertensive agents. US Patent 4,663,334. 1987.

5. Kozhevnikov DN, Kozhevnikov VN, Prokhorov AM, Ustinova MM, Rusinov VL, Chupakhin ON, Aleksandrov GG, König B. Consecutive nucleophilic substitution and aza Diels - Alder reaction - an efficient strategy to functionalized 2,2'-bipyridines. Tetrahedron Lett. 2006;47(6): 869-872.

DOI: $10.1016 /$ j.tetlet.2005.12.006

6. Kopchuk DS, Nikonov IL, Khasanov AF, Giri K, Santra S, Kovalev IS, Nosova EV, Gundala S, Venkatapuram P, Zyryanov GV, Majee A, Chupakhin ON. Studies on the interactions of 5-R-3-(2-pyridyl) - 1,2,4-triazines with arynes: inverse demand aza-Diels - Alder reaction versus aryne-mediated domino process. Org Biomol Chem. 2018;16:5119-5135.

DOI: $10.1039 / \mathrm{C} 8 \mathrm{OB} 00847 \mathrm{G}$

7. Kopchuk DS, Krinochkin AP, Khasanov AF, Kovalev IS, Slepukhin PA, Starnovskaya ES, Mukherjee A, Rahman M, Zyryanov GV, Majee A, Rusinov VL, Chupakhin ON, Santra S. An Efficient Cyanide-Free Approach towards 1-(2-Pyridyl) isoquinoline-3-carbonitriles via the Reaction of 5-Phenacyl-1,2,4-triazines with 1,2-Dehydrobenzene in the Presence of Alkyl Nitrites. Synlett. 2018;29:483-488.

DOI: $10.1055 / \mathrm{s}-0036-1590961$

8. Prokhorov AM, Slepukhin PA, Kozhevnikov DN. $\mathrm{CuCl}_{2}$ induced reactions of 6-ethynyl- and 6-cyano-5-aryl-2,2' - bipyridines with various $\mathrm{N}$ - and O-nucleophiles 
in comparison with the reactions of relative 1,2,4-triazines. J Organometallic Chem. 2008;693:1886-1894.

DOI: 10.1016/j.jorganchem.2008.02.016

9. Kopchuk DS, Nikonov IL, Krinochkin AP, Kovalev IS, Zyryanov GV, Rusinov VL, Chupakhin ON. One-pot non-cyanide synthesis of 1-(pyridin-2-yl)isoquinoline3-carbonitrile by reaction of 1-phenyl-2-[6-phenyl-3-(pyridin-2-yl) - 1,2,4-triazin5 -yl] ethanone with 1,2-dehydrobenzene in the presence of isoamyl nitrite. Russ J Org Chem. 2017;53(6):959-961.

DOI: $10.1134 /$ S1070428017060264

10. a) Krinochkin AP, Kopchuk DS, Kovalev IS, Zyryanov GV, Rusinov VL, Chupakhin ON. One-Step synthesis of 5-methyl-1,2,4-triazines by the transformation of their 5-phenacyl derivatives. Russ J Org Chem. 2019;55(2):266-268. DOI: 10.1134/ S1070428019020210; b) Krinochkin AP, Kopchuk DS, Kim GA, Shevyrin VA, Santra S, Rahman M, Taniya OS, Zyryanov GV, Rusinov VL, Chupakhin ON. Watersoluble luminescent lanthanide complexes based on C6-DTTA-appended 5-aryl2,2'-bipyridines. Polyhedron. 2020;181:114473.

DOI: $10.1016 /$ j.poly.2020.114473

11. Shoetsu K, Satoshi F, Hiroshi Y. Studies on as-Triazine Derivatives. V. Synthesis and Hydration of Alkynyl-1,2,4-triazines. Heterocycles. 1984;22(10):2245-2248.

12. Prokhorov AM, Makosza M, Chupakhin ON. Direct introduction of acetylene moieties into azines by SNH methodology. Tetrahedron Lett. 2009;50(13):1444-1446.

DOI: $10.1016 /$ j.tetlet.2009.01.070

13. Carroll FI, Kotturi SV, Navarro HA, Mascarella SW, Gilmour BP, Smith FL, Gabra $\mathrm{BH}$, Dewey WL. Synthesis and pharmacological evaluation of phenylethynyl $[1,2,4]$ methyltriazines as analogues of 3-methyl-6-(phenylethynyl)pyridine. J Med Chem. 2007;50(14):3388-3391.

DOI: $10.1021 / j m 070078 \mathrm{r}$

14. Khasanov AF, Kopchuk DS, Kovalev IS, Taniya OS, Zyryanov GV, Rusinov VL, Chupakhin ON. Reaction of lithium 2-arylethynides with 6-aryl-3-(2-pyridyl) 1,2,4-triazines as an access to 6-aryl-5-arylvinyl-3-(2-pyridyl) - 1,2,4-triazines. Mendeleev Commun. 2015;25(5):332-333.

DOI: $10.1016 /$ j.mencom.2015.09.003

15. Kozhevnikov VN, Shabunina OV, Kopchuk DS, Ustinova MM, König B, Kozhevnikov DN. Facile synthesis of 6-aryl-3-pyridyl-1,2,4-triazines as a key step towards highly fluorescent 5-substituted bipyridines and their $\mathrm{Zn}$ (II) and $\mathrm{Ru}(\mathrm{II})$ complexes. Tetrahedron. 2008;64:8963-8973.

DOI: $10.1016 /$ j.tet.2008.06.040 